\title{
Interaction between Competition and Predation in Cave Stream Communities
}

\author{
by
}

\author{
David C. CULVER*
}

In most cave streams in the Appalachians, competition is a more important interaction than predation. This observation is justified because in most caves in the Appalachians potential predator populations consist of only an occasional salamander or crayfish near the cave entrance (see Barr 1961; Franz and Slifer 1971; and Holsinger 1964). However, there are a few caves in the Powell Valley of Virginia and Tennessee that have a large, permanent population of the salamander Gyrinophilus porphyriticus. The gilled larvae of porphyriticus live in cave streams several years before transforming into adults. During the larval period, they subsist, at least in cave streams, almost entirely on the invertebrates they capture in the cave stream. The appetite of porphyriticus in the laboratory can be quite large: one larva ate 27 of 30 isopods offered to it in a five day period. Since the natural density of isopods and amphipods is usually less than 30 per $\mathrm{m}^{2}$, the potential effect of porphyriticus in cave streams is very great, especially since reproductive rates of the prey are low.

The purpose of this study is twofold. The first is the determination of the effect of predation by $G$. porphyriticus larvae on their prey species (the isopod Asellus recurvatus and the amphipod Crangonyx antennatus), which are themselves competing. Since the work of Paine (1966) showing that predators can increase species diversity, there has been considerable interest in determining whether predation generally increases diversity in a community. Counterexamples have been found (see Addicott 1974), and May (1973a) has provided a theoretical basis for understanding the role of the interaction of competition and predation in affecting species diversity. One of the important points he makes is that there is no general rule about the effect predators will have on the diversity of prey species. The present study shows that the effect of predation depends on environmental heterogeneity, and that diversity of prey is increased by predation in complex habitats, but not in simple ones. I will attempt to assess not just predation by the salamander (Culver 1973a) or the competitive interactions of the crustacean prey (Culver 1973b), but rather I will emphasize the interaction of the two.

The second purpose of this study is to put forward some explanations for the rarity of porphyriticus in caves. Porphyriticus may be missing from many caves because of the island-like nature of caves (Culver 1970,1971), but this does not explain why most populations of this salamander in caves consist of only a few

* Department of Biological Sciences, Northwestern University, Evanston, Illinois 60201, U.S.A. 
DAVID C. CULVER

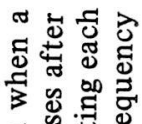

뎡

움영

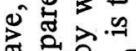

نَ.

nt)

늘 을

记灵

$\sum{ }^{N}=$

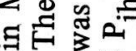

क ن

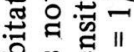

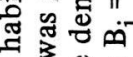

范柴

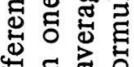

단

ठ

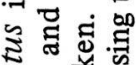

노웛

क

击

ऍ芩芯

ิำㄴำ

柴起

ง

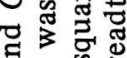

สี ซึ

究出。

氙造

ई ปิ

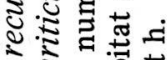

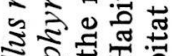

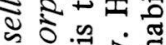

ए :

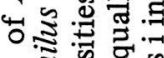

谣

ฐす

施泀

命芯芯

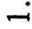

苟

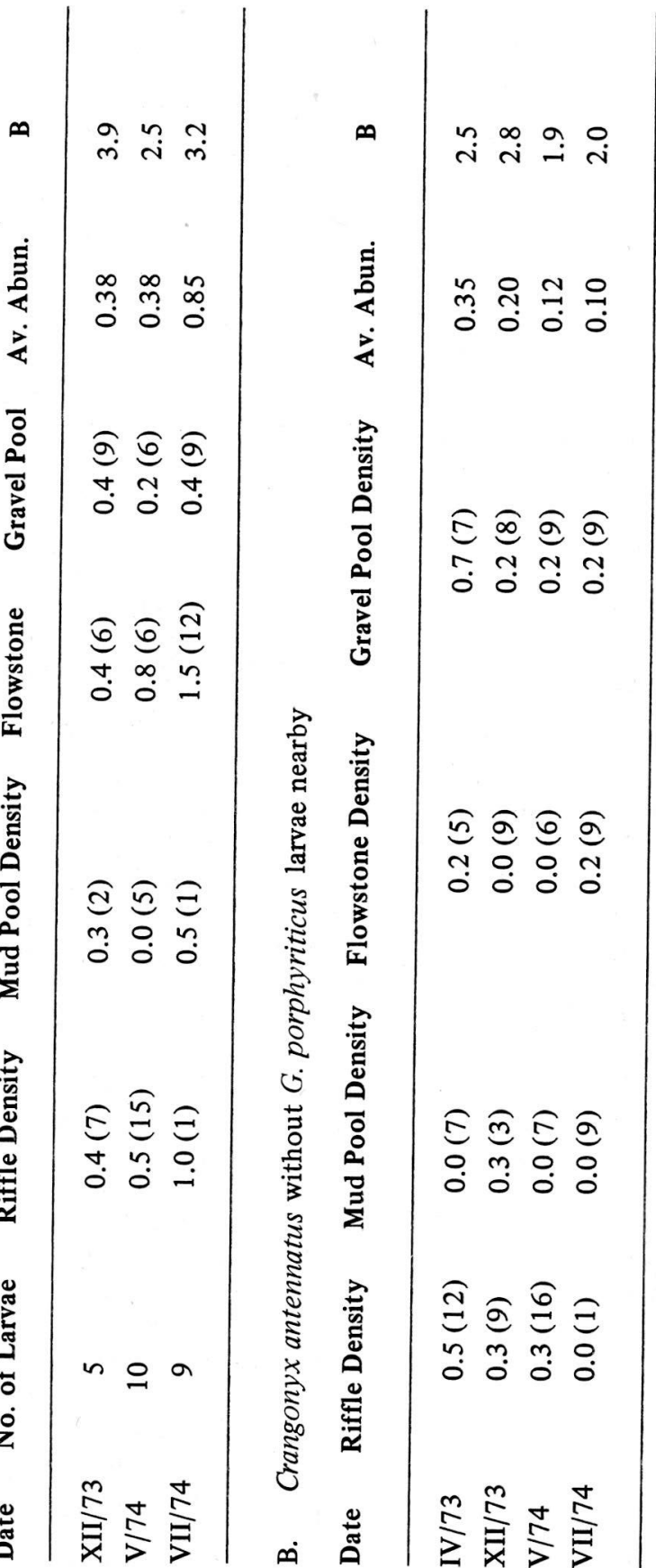




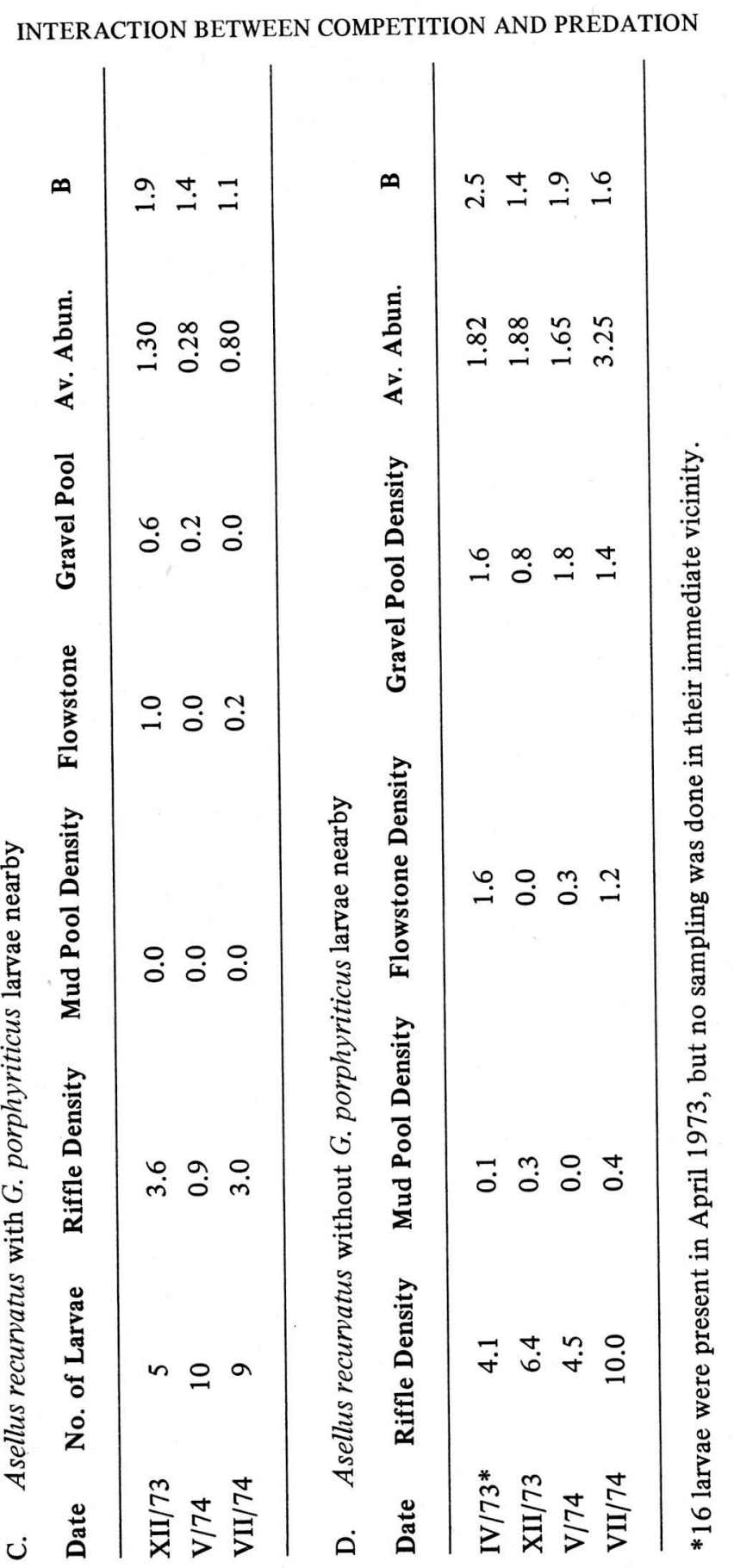


scattered individuals. As will be seen, this appears to be a consequence of the ease of invasibility by the predator and the difficulty in reaching a stable equilibrium with the prey, which results from changes in prey availability.

\section{METHODS AND MATERIALS}

Most of the data reported here were collected in McClure's Cave in Lee County, Virginia. McClure's Cave is a small stream passage cave at the end of a small blind valley. The small stream in the cave, which enters the cave from an inaccessible side passage, flows over mud, gravel, and rocks and can be followed for $300 \mathrm{~m}$ before the cave passage gets too low to follow. Four main habitats occur in the cave: riffles, mud-bottomed pools, gravel-bottomed pools, and water flowing over travertine and flowstone. The riffle-pool structure typical of many small streams (Leopold et al. 1964) is incompletely developed, perhaps because of the presence of considerable amounts of travertine and flowstone. The cave was sampled at four times--20 April 1973, 17 December 1973, 14 May 1974, and 30 July 1974. On each trip the number of salamander larvae in the stream was recorded and the position of each larvae was marked by a pile of rocks. Salamanders were counted while walking and crawling downstream because they often hide under rocks when the water is disturbed. Between 23 and 32 random square foot $\left(0.09 \mathrm{~m}^{2}\right)$ samples were taken of the prey in each of the four habitats on the trip out of the cave (Table 1). In addition, on the last three trips one to four square foot samples were taken within one meter of each salamander larva. These samples were taken to assess local prey depletion by a larva. In each sample, loose rocks and gravels were individually checked, and a tea strainer placed immediately downstream collected any animals that were dislodged. There was generally not sufficient water flow to use a Surber sampler. The entire stream down to a low water crawl was sampled. In July 1974, the upstream 50 meters of the stream was nearly dry with only isolated pools remaining. Few predators or prey were present and the section was not sampled.

, Data were also taken in Sweet Potato Cave, a small cave in Lee County, where there is a series of cascading rimstone pools (gours) which disappears into a passage too low to follow. The pools were sampled on 21 April 1973 and 8 August 1973. All censusing was done visually.

\section{RESULTS AND DISCUSSION}

Table 1 lists the mean densities of Asellus recurvatus and Crangonyx antennatus in the four habitats both with and without nearby porphyriticus larvae. $G$. porphyriticus and its two crustacean prey are the only species known from the cave stream except for several lumbriculid oligochaetes collected by David Cook in May 1974 , and occasional dense concentrations of the flatworm Sphalloplana virginiana. Cave flatworms are supposedly predators of amphipods and isopods (Mohr and Poulson 1966), and salamanders may eat flatworms. However, over 90 percent of 
the flatworms that I have seen in the cave were on the surface film of isolated pools with no salamanders, isopods, or amphipods. These concentrations of flatworms were probably recently hatched from cocoons, and seemed to be feeding on the microbial scum on the surface of the pools. The role of flatworms in cave stream communities will be the subject of a later paper.

The best available estimate of the relative frequency of riffles, mud pools, gravel pools, and flowstone is the total number of times each habitat was sampled in areas not near salamander larvae (Table 1B) on the four trips to McClure's Cave. The relative frequencies of the four habitats are not significantly different from equality $\left(\chi_{(3)}^{2}=2.57, \mathrm{P}<0.90\right)$ and so when overall densities are calculated, the habitats are assumed to be in equal proportions.

The density of $A$. recurvatus is reduced markedly in the immediate vicinity of a salamander larva for each sampling period (Table 1C, D). The reduction in density was 31 percent in December 1973, 83 percent in May 1974, and 75 percent in July 1974 all of which are significant decreases $(t-$ test, $P>0.95)$. On the other hand, the abundance of $C$. antennatus increased when salamander larvae are nearby (Table 1A,B). The increase in density was 90 percent in December 1973, 220 percent in May 1974, and 750 percent in July 1974. The July increase was significantly different $(P>0.95)$, the other two were not. This increase is not because porphyriticus does not eat $C$. antennatus. Porphyriticus readily eats $C$. antennatus (although $A$. recurvatus is preferred) in the laboratory (Culver 1973a), and it is found in the guts of larvae taken from the cave (Table 2). Rather, the increase occurs because $C$. antennatus experiences intense competition from $A$. recurvatus (Culver 1973b), and predation on A. recurvatus reduces its effect on C. antennatus. On the other hand, recurvatus is less affected by competition with antennatus

Table 2. Gut contents of four Gyrinophilus porphyriticus larvae from McClure's Cave.

\begin{tabular}{lc|c|c} 
& $\begin{array}{c}\text { No. of } C \text {. antennatus } \\
\text { in gut }\end{array}$ & $\begin{array}{c}\text { No. of } A \text {. recurvatus } \\
\text { in gut }\end{array}$ & $\begin{array}{c}\text { Relative frequency of } C \text {. antennatus } \\
\text { in nearby accessible habitats }\end{array}$ \\
\cline { 1 - 2 } I * & 0 & 2 & 0.40 \\
II & 1 & 1 & 0.00 \\
III & 1 & 0 & 1.00 \\
IV & 0 & 0 & None \\
Average & 0.5 & 0.75 & 0.35 \\
\hline
\end{tabular}

*A portion of one lumbricid was also in the gut. 
Table 3. Distribution of Asellus recurvatus and Crangonyx antennatus in rimstone pools in Sweet Potato Cave. Pools are classified according to whether or not a.porphyriticus larva was present.

\begin{tabular}{lcccc} 
& $\begin{array}{c}\text { Crangonyx } \\
\text { Present }\end{array}$ & $\begin{array}{c}\text { antennatus } \\
\text { Absent }\end{array}$ & $\begin{array}{c}\text { Asellus } \\
\text { Present }\end{array}$ & $\begin{array}{c}\text { recurvatus } \\
\text { Absent }\end{array}$ \\
\hline Predator Absent & $11^{*}$ & 0 & 5 & 6 \\
\cline { 2 - 5 } Predator Present & $2 * *$ & 2 & 0 & 4 \\
\hline
\end{tabular}

* Abundance of C. antennatus ranged from 10 to more than 40 in a pool.

** Abundance of C. antennatus was 10 or less in a pool.

(Culver 1973b). The amount of decrease of $A$. recurvatus and the amount of increase of $C$. antennatus vary greatly, but the amount of change is large in all cases. There is also a hint of reciprocity between the decrease of $A$. recurvatus and the increase of $C$. antennatus. The smallest decrease in recurvatus occurs at the same time (December 1973) as the smallest increase in C. antennatus. This is also consistent with the idea that the two species compete.

The populations in Sweet Potato Cave provide an interesting contrast with those in McClure's Cave. The only available habitat is rimstone pools (gours), the rough equivalent of mud pools in McClure's Cave. In those pools where larvae are present, no recurvatus are present, and the density of antennatus is reduced by over $\mathrm{x} 50$ percent (Table 3). In McClure's Cave, that part of the prey population living in riffles and on flowstone is inaccessible to the salamander predators because the larvae apparently require still water in order to detect prey (Cooper and Cooper 1968, Culver 1973a), and consequently, the salamander larvae rarely occur in these habitats (Fig. 1). Thus there is a refugium for prey that will in general act to stabilize the predator-prey interaction (Rosenzweig and MacArthur 1963). In Sweet Potato Cave there is no refugium.

Even though only two prey species are involved, the changes in density can be translated into changes in diversity. The point diversity (see Sklobodkin and Fishelson 1974) in McClure's Cave increases when salamander larvae are nearby because the densities of the two prey become similar, i.e., equitability increases. The point diversity in Sweet Potato Cave decreases because A. recurvatus is not present when salamander larvae are nearby.

The habitat niches of both $C$. antennatus and $A$. recurvatus show changes when porphyriticus larvae are nearby (Fig. 1). To calculate habitat frequencies, the average frequency of each species for each habitat for the three sampling dates was 


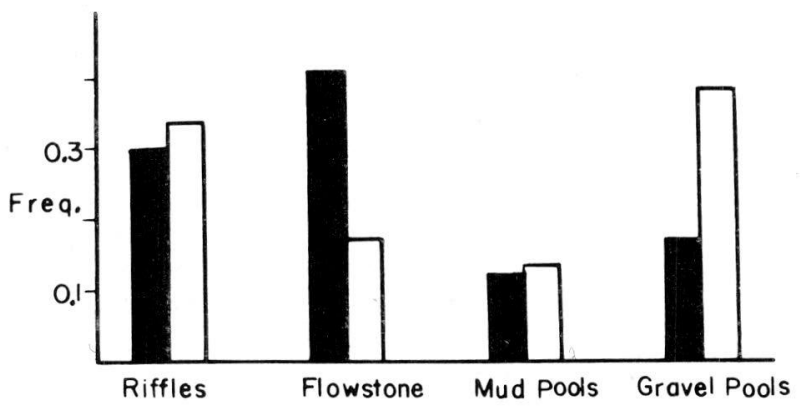

Crangonyx antennatus
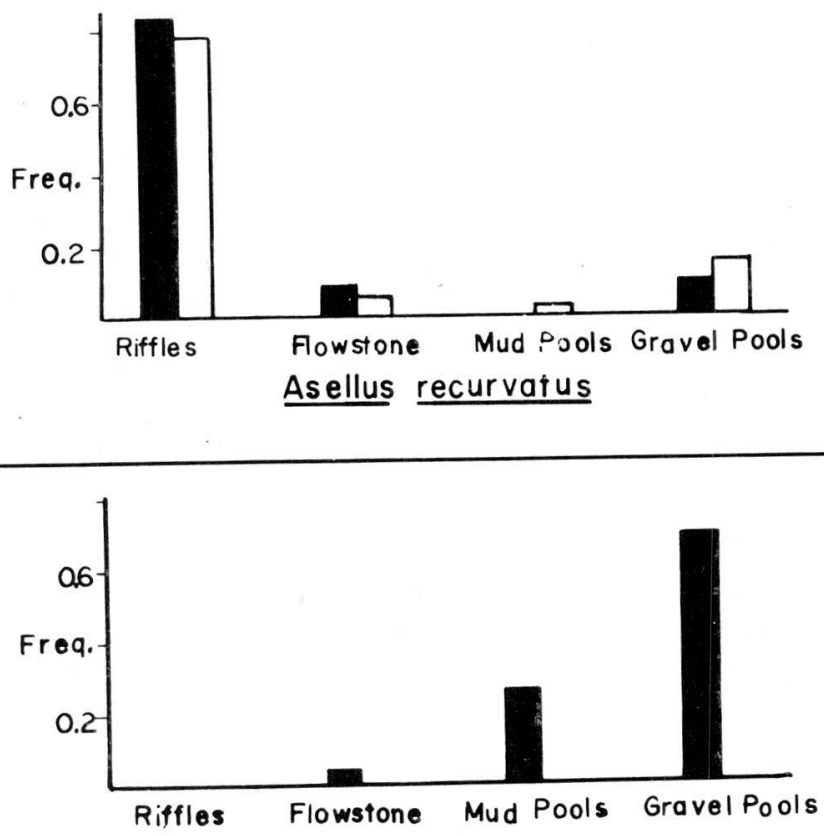

\section{Gyrinophilus porphyriticus}

Fig. 1. Habitat niches of Crangonyx antennatus, Asellus recurvatus, and Gyrinophilus porphyriticus in McClure's Cave. The solid bars represent habitat niches of the prey when a porphyriticus larva is nearby. The open bars represent habitat niches of the prey when a porphyriticus larva is not nearby. The frequencies displayed in the figure are the average frequencies of occurrence for all sampling dates. Niche breadths are as follows:
C. antennatus
A. recurvatus
G. porphyriticu
3.3
1.5
G. porphyriticus

Predator Nearby

Predator Not Nearby

3.3

1.6 
used. Niche breadths were calculated according to the following formula (Levins 1968):

$$
\mathrm{B}_{\mathrm{i}}=1 \int_{\mathrm{h}}^{\Sigma} \mathrm{P}_{\mathrm{ih}}^{2}
$$

where $\mathrm{P}_{\mathrm{ih}}$ is the frequency of species $\mathrm{i}$ in habitat $\mathrm{h}$. The preferred habitat of recurvatus is clearly riffles, and it has a narrow niche whether or not a predator is present. This is in accord with the general principle that aquatic cave organisms prefer riffles (Culver 1973b). When salamander larvae are nearby, the frequency of isopods in the two habitats where salamanders occur (mud pools and gravel pools) decreases and causes a small reduction in niche breadth (from 1.6 to 1.5). The situation with antennatus is more complex. Unlike recurvatus antennatus has a broad habitat niche (3.3. when larvae are nearby, and 3.3. when they are not) (Fig. 1). However, like recurvatus, the preferred habitat of antennatus is probably riffles (Culver 1973b). In areas not near a larva antennatus is common in non-riffle habitats. This is because of the high density of the isopod competitor in riffles. When larvae are nearby, we would expect an increase in frequency in riffles and on flowstone, but in fact only the frequency on flowstone increases. Few salamanders are on flowstone, and perhaps tlowstone is preferred by antennatus. Surprisingly, the frequency in gravel pools, but not in mud pools, decreases---both frequencies were expected to decrease. $C$. antennatus may avoid predators by burrowing in the mud (Holsinger and Holsinger 1971).

The difference between the total niche breadth and average niche breadth was used by Levins et al. (1973) to measure niche plasticity. The average niche breadth is simply the average of niche breadths for each sampling dat (see Table 1), and total niche breadth is computed by using the average habitat frequency over all sampling dates (Fig. 1). If niches are different at different times, total niche breadth will be greater than average niche breadth. If niches do not change, the two will be equal. The only case where niche plasticity was found was for antennatus when predators were not nearby. In this case, plasticity seems to measure niche uncertainty brought about by exclusion by recurvatus of antennatus from a preferred habitat.

Since that part of the prey population in McClure's Cave that occurs on flowstone and in riffles is inaccessible to salamander larvae, relative predation rates depend not only on prey preferences, but also on that proportion of the prey population that is accessible to salamander larvae. From laboratory experiments on feeding preference, it was found that porphyriticus larvae take recurvatus three times as frequently as it takes antennatus (Culver 1973a). To obtain relative predation rates, these frequencies $(0.75$ and 0.25$)$ must be multiplied by accessible proportion of the population, i.e., the proportion in mud pools and in gravel pools. This calculation is shown in Table 4 for two situations--for a predator invading a previously unexploited area and for a predator present in an area. For both situations, there is no significant difference between the predation rates on antennatus and recurvatus. However, the potential predation rate on antennatus by a larvae 
invading a previously unexploited area is significantly greater than the potential predation rate on antennatus by a resident $(\mathrm{t}=2.26, \mathrm{P}>0.95)$. The difference between the two rates for $A$. recurvatus is significant only at the 90 percent level $(\mathrm{t}$ $=1.76$ ).

\section{DISCUSSION}

\section{Invasibility}

In a general way, there is a clear distinction between a species invading a community, and the stability of a community with all species at their equilibrium population sizes. This distinction carries over into theoretical models of species interactions as well. In order for species $\mathrm{i}$ to invade a community, $\mathrm{dN}_{\mathrm{i}} / \mathrm{dt}$ (the rate of change of population size) must be positive when $N_{i}$ is small, or at least the invading individuals in the propagule must obtain sufficient food to maintain themselves but without sufficient food for reproduction. In order for a community to

Table 4. Relative predation rates by Gyrinophilus porphyriticus on Asellus recurvatus and Grangonyx antennatus. The accessible proportion of the population is the proportion in mud pools and gravel pools. These proportions are multiplied by 0.25 in the case of $C$. antennatus and by 0.75 in the case of $A$. recurvatus to correct for prey preferences. This number is the relative predation rate. Invasion refers to the situation when a predator invades an unexploited area; resident refers to the situation when a predator has been in the area for some time.

Relative Predation Rates

C. antennatus

Invader antennatus Invader

\section{April 1973}

December 1973

May 1974

July 1974

A. recurvatus

Resident Invader Resident

\begin{tabular}{lllll} 
Mean & 0.126 & 0.072 & 0.150 & 0.075 \\
Variance & 0.0005 & 0.0017 & 0.0020 & 0.0047 \\
Standard error & 0.011 & 0.023 & 0.0225 & 0.040 \\
\hline
\end{tabular}

$\begin{array}{llll}0.125 & - & 0.172\end{array}$


have a stable equilibrium point, population sizes must return to this equilibrium point following small perturbations. However, for most of the models clustered around the 'community matrix' concept (Levins 1968; May 1973a), the formal criteria for invasibility and stability are identical (Strobeck 1973) because of the strong linearity assumptions in these models. The data on predation rates (Table 4) suggest, although the formal criteria for invasibility and stability may be identical, the parameters (the predation rates) themselves change. That is, potential predation rates are greater at the time of invasion than at equilibrium. This in turn suggests that, in the field, most porphyriticus populations should consist of only a few individuals (successful invasions) and only a few populations should consist of more than a few individuals (roughly equivalent to equilibrium populations). This is in fact the case (Fig. 2). This is also consistent with the small number of prey items in salamander guts (Table 2).

This phenomenon of invasion being easy compared to establishing a stable equilibrium may be a general characteristic of predators that eat prey occurring in a heterogeneous environment where habitats differ in their accessibility to predators. Consider the situation prior to invasion by a predator. Even if a community does not have the maximum stable number of competing prey species, those species that are present are likely to expand their habitat niches so that most available habitats are used by one or more species. This is the well documented phenomenon of habitat release (Diamond 1970; MacArthur 1972). By assumption, some of the habitats are inaccessible to a predator that invades, and some are vulnerable. When a predator invades, there will be a relatively abundant food supply. As the predator

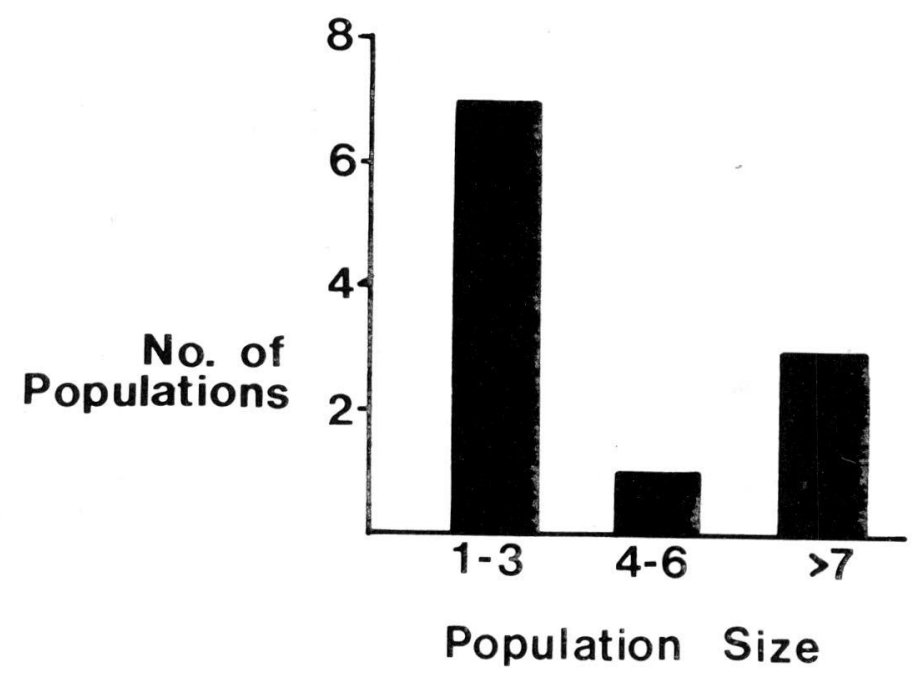

Fig. 2. Distribution of population sizes of Gyrinophilus poprphyriticus larvae and adults in Powell Valley Caves. 
population grows, the available food supply contracts since a greater proportion of prey will be in refugia. This process may result in the extinction of some prey populations, but from the point of view of the predator, the total amount of food available decreases as its population grows. This may lead to instability in two ways. First, there may not be enough food available for the predators to reproduce, or second, time lags in predator population response may cause the predator population to overshoot and then crash (May 1973b).

The situation with competitors is likely to be quite different. Once again consider an unsaturated community. Habitat release will act to fill most available habitats. When a competitor invades, it is likely to face intense competition, or at least greater habitat niche overlap. If the initial invasion is successful, population increase may become progressively easier as the habitat niches of the resident species contrast, which would cause a reduction in interspecific competition. As the population increases, intraspecific competition increases and slows growth rates. However, intraspecific competition does not cause a negative growth rate when population size is below the carrying capacity, whereas interspecific competition can, especially (as is argued above) when population size is small. Since niche release is much less frequent for species that eat different foods in the same habitat than for species eating the same food in different habitats (MacArthur and Wilson 1967), we would not expect extra difficulty for invasion when niche separation is primarily by diet. However, for guilds of species for which habitat separation is important, such as prey species discussed in this paper (see Culver 1973b), one would expect that most populations would be close to equilibrium rather than in the early stages of invasion. Of the 19 prey populations in the 11 caves with salamander populations, only one ( $C$. antennatus in Surgeners Cave) is small enough that it is possible that it is in the early stages of invasion, in contrast to the salamander populations (Fig. 2).

\section{Stability}

In this section the stability of the predator-prey system and the prey system alone will be analyzed. To do this I will start with the following equations (Cramer and May 1971):

$$
\begin{aligned}
& \frac{\mathrm{dH}_{1}}{\mathrm{dt}}=\mathrm{r}_{1} \mathrm{H}_{1}\left(1-\frac{\mathrm{H}_{1}}{\mathrm{~K}_{1}}-\frac{\alpha_{12} \mathrm{H}_{2}}{\mathrm{~K}_{1}}\right)-\beta \mathrm{H}_{1} \mathrm{P}_{3} \\
& \frac{\mathrm{dH}_{2}}{\mathrm{dt}}=\mathrm{r}_{2} \mathrm{H}_{2}\left(1-\frac{\mathrm{H}_{2}}{\mathrm{~K}_{2}}-\frac{\alpha_{21} \mathrm{H}_{1}}{\mathrm{~K}_{2}}\right)-\beta \mathrm{H}_{2} \mathrm{P}_{3} \\
& \frac{\mathrm{dP}}{\mathrm{dt}}=\mathrm{P}_{3}\left(-\mathrm{d}+\gamma \mathrm{H}_{2}+\gamma \mathrm{H}_{3}\right)
\end{aligned}
$$

where $\mathrm{H}_{1}$ is the population size of $C$. antennatus, $\mathrm{H}_{2}$ the population size of $A$. recurvatus, $\mathrm{P}_{3}$ the population size of $G$. porphyriticus, $\mathrm{r}_{\mathrm{i}}$ the rate of increase of 
species $i, K_{i}$ the carrying capacity of species $i, \alpha_{i j}$ the effect of competitor $j$ on species $i$, the predation rate of porphyriticus, $d$ the death rate of the predator, and the rate of increase in the predator population brought about by eating a prey organism. The assumptions involved with using such simplified equations have been discussed extensively (see Gilpin and Justice 1973; MacArthur 1972; May 1973; Maynard Smith 1974; Neill 1974). One assumption should be especially noted--the equations are assumed to hold near equilibrium, therefore the community is assumed to be near equilibrium. The linearity of predation $\left(\mathrm{H}_{\mathrm{i}} \mathrm{P}_{3}\right)$ seems to be a reasonable assumption. In the laboratory, the functional response curve (Holling 1965) of porphyriticus is linear when only one prey species is present (Culver unpublished). While switching may occur (Lawton et al. 1974; Murdoch and Marks 1973), the failure of conditioning experiments to produce changes in prey preference of porphyriticus (Culver 1973a) indicates that switching is unlikely. The most obvious inaccuracy is in equation (3). Since the adult stage of porphyriticus does not live in the stream, there should be, at a minimum, time lags in some of the terms in equation (3). Bishop (1941) believes that the larval period of porphyriticusin springs lasts three years, and one year as an adult before sexual maturity is reached, and it is likely that cave populations have an even longer life history (see Brandon 1971).

The effect of using equation (3) without time lags will be to overestimate the stability of the predator-prey system (see May 1973b).

The data in Table 4 indicate that the predation rates on the two prey are not significantly different, and it also appears that the carrying capacities of $C$. antennatus and $\mathrm{A}$. recurvatus $\left(\mathrm{K}_{1}\right.$ and $\left.\mathrm{K}_{2}\right)$ are very similar, according to two independent estimates. First, in a previous paper (Culver 1973b), I claimed that the carrying capacity for the prey species is directly proportional to the inverse of the washout rate of individuals from a riffle in an artificial stream. The ratio of the carrying capacities in this case is 0.96 . Second, by combining a direct count of individuals $\left(\mathrm{N}_{\mathrm{i}}\right)$ in a section of stream in Gollahan's No. 1 Cave with competition coefficients determined in the laboratory, the ratio of $\mathrm{K}_{1}$ and $\mathrm{K}_{2}$ was found to be 1.01. Finally, the competition coefficients $\left(\alpha_{\mathrm{ij}}\right)$ were calculated in Culver $(1973 \mathrm{~b})--\alpha_{12}=1.0$, $\alpha_{21}=0.3$.

At equilibrium, equation (1) to (3) are, in matrix form:

$\left[\begin{array}{l}\mathrm{K}_{1} \\ \mathrm{~K}_{2} \\ -\mathrm{d}\end{array}\right]=\left[\begin{array}{ccc}1 & \alpha_{12} & \frac{\beta \mathrm{K}_{1}}{\mathrm{r}_{1}} \\ \alpha_{21} & 1 & \frac{\beta \mathrm{K}_{2}}{\mathrm{r}_{2}} \\ -\gamma & -\gamma & 0\end{array}\right]\left[\begin{array}{c}\hat{\mathrm{H}}_{1} \\ \hat{\mathrm{H}}_{2} \\ \hat{\mathrm{P}}_{3}\end{array}\right]$




$\left.\begin{array}{l}\mathrm{or} \\ \mathrm{K} \\ -\mathrm{d}\end{array}\right]=\left[\begin{array}{ccc}1.0 & 1.0 & \frac{\beta \mathrm{K}}{\mathrm{r}_{1}} \\ 0.3 & 1.0 & \frac{\beta \mathrm{K}}{\mathrm{r}_{2}} \\ -\gamma & -\gamma & 0\end{array}\right]\left[\begin{array}{l}\hat{\mathrm{H}}_{1} \\ \hat{\mathrm{H}}_{2} \\ \hat{\mathbf{P}}_{3}\end{array}\right]$

May and his colleagues (May 1971, 1973a; Cramer and May 1971) have done a complete stability analysis of systems described by equations like the ones discussed above, and their results will be followed closely.

The stable coexistence of a system of competitors is subject to two constraints. First, the equilibrium must be stable to small perturbations, and second, the equilibrium must lie in that part of the phase space where all population sizes are positive. This second constraint has been called feasibility by Roberts (1974). This distinction can be made clearer by a brief consideration of two-species competition models. In terms of the standard isocline graphs of two-species competition (e.g., Krebs 1972, p. 216), stability requires that the slope of the isocline for species 1 ( $\frac{\mathrm{dN}_{1}}{\mathrm{dt}}$ $=0)$ be less than the slope of the isocline for species $2\left(\frac{\mathrm{dN}_{2}}{\mathrm{dt}}=0\right)$. Feasibility requires that the intersection of the two isoclines must be in the upper right quarter of the phase plane. The standard graphical treatment of two species competition partially blurs this distinction (Vandermeer pers. comm.). None-feasible systems are not mathematical artifacts without ecological importance (Roberts 1974), because non-equilibrium states can occur with all population sizes positive (Ricklefs 1973, p. 515). Recent theoretical work has emphasized stability rather than feasibility (Levins 1970; May 1972) in part because stability analysis indicates complexity generally decreases stability, counter to the usual biological intuition (Hutchinson 1959). Feasibility may be important in real communities as well, because most randomly constructed unstable communities are not feasible as well (Roberts 1974). In the paragraphs below, both feasibility and stability of the McClure's Cave community will be examined.

Translating May's stability criteria in terms of equation (5) the predator-prey system will be stable if

$$
0.7\left(\frac{\mathrm{r}_{2} \hat{\mathrm{H}}_{2}}{\mathrm{~K}}\right)>0
$$

which will be positive if $\mathrm{H}_{2}$ is positive. In terms of the interaction coefficients, the system is always stable. The prey system will be stable if

$$
0.7\left(\frac{\mathrm{r}_{1} \mathrm{r}_{2} \hat{\mathrm{H}}_{1} \hat{\mathrm{H}}_{2}}{\mathrm{~K}^{2}}\right)>0
$$


Table 5. Equilibrium population sizes calculated from equation (5). See text for details.

Species

Salamanders Present

Salamanders Absent

Crangonyx antennatus $\frac{(-\gamma \mathrm{K}+\mathrm{d})\left(\frac{1}{\mathrm{r}_{1}}-\frac{1}{\mathrm{r}_{2}}\right)}{0,7 \gamma / \mathrm{r}_{1}}$

$\mathrm{O}$

Asellus recurvatus

$$
\frac{\frac{-(\gamma K-d)}{r_{2}}+\frac{(\gamma K-0.3 d)}{r_{1}}}{\frac{0.7 \gamma}{d}}
$$

K

Gyrinophilus

porphyriticus

$$
\frac{\gamma \mathrm{K}-\mathrm{d}}{\gamma \beta \mathrm{K} / \mathrm{r}_{1}}
$$

which will also always be stable if population sizes are positive. It is the equilibrium population sizes, i.e., the feasibility, that set real constraints on the system (Table 5). These constraints operate either by making a positive population size impossible, or by reducing population size to the point where chance fluctuation are likely to cause extinction. For the predator-prey system, the equilibrium population size of any of the species may be zero, depending on the particular value of the parameters (Table 5). For the prey system alone, the equilibrium population size of $C$. antennatus is calculated to be zero, when in fact it is small but positive (Table 1). This indicates that either $\alpha_{12}$ is slightly less than one, or $K_{1}$ is slightly greater than $\mathrm{K}_{2}$. If the population sizes calculated in Table 5 are taken to be completely accurate, the predator-prey system is more stable. A more general point, and a more robust conclusion is that the reduction in population size is more likely to cause extinction than the instability of the equilibrium.

\section{Patchiness}

The major environmental difference between McClure's Cave and Sweet Potato Cave is that the habitat in Sweet Potato Cave consists of a series of highly homogeneous patches (rimstone pools, or gours) whereas the habitat in McClure's Cave is heterogeneous (riffles, flowstone, etc.) and patchy (e.g., different pools are separated from each other). In other caves similar to McClure's, recurvatus and antennatus persist in the absence of porphyriticus. Thus it seems that the habitat heterogeneity of these streams allows for continued persistence of both the prey 
system and the predator-prey system. In Sweet Potato Cave, it is likely that the combination of the two prey species or the complete predator-prey system is unstable if one pool is considered in isolation. Consider the two prey species without the predator. The pools are very homogeneous, and we would expect competitive exclusion on theoretical grounds, especially since there is interference competition between the two prey species (Culver 1973b). However, the time to exclusion may be very long (Miller 1967). In any case, there will be migrants both from water seeping into the cave and from other pools. Theoretically, migration can result in the regional coexistence of species that cannot coexist indefinitely in a single patch (Levins and Culver 1971; Slatkin 1973; Levin 1974). This seems to be happening in Sweet Potato Clave. That is, the expected time to extinction is greater than the expected time between migrations. When a predator is present, population sizes are decreased (especially for recurvatus) and extinction times become less than the times between migrations.

Finally, the role of competition and predation in both communities can be compared. In both caves, competition decreases population sizes-antennatus is more affected in McClure's Cave while recurvatus seems to be most affected in Sweet Potato Cave. If reduced population size increases the chance of extinction (MacArthur and Wilson 1967), then competition destabilizes the community. Predation in McClure's Cave tends to equalize population sizes of the two species, and thus reduces the chance of extinction. It is a stabilizing force (Paine 1971). In Sweet Potato Cave, it reduces both prey populations and this is a destabilizing force (Addicott 1974).

\section{SUMMARY}

Predation by salamander larvae (Gyrinophilus porphyriticus) reduces the density of one of its prey (the isopod Asellus recurvatus) but increases the density of the other (the amphipod Crangonyx antennatus in a Virginia cave stream. This happens because predation on the isopod reduces its competitive effect on the amphipod. Both prey populations tend to occur more frequently in refugia when predators are present. In another cave where there are no prey refugia, the predator reduces the density of both species. It appears that it is easier for a predator to invade a community than to reach a stable equilibrium with the prey, if the prey have refugia. Persistence of the prey system and the predatorprey system is constrained more by low population sizes than by the instability of the interaction coefficients.

\section{RESUME}

La prédation excercée par les larves de Salamandre (Gyrinophilus porphyriticus) fait décroitre la densité d'une de ses proies (l'Isopode Asellus recurvatus), mais fait s'accroitre celle d'une autre (l'Amphipode Crangonyx antennatus) dans un cours d'eau souterrain de Virginie. Ceci est dû à ce que la prédation sur l'Isopode diminue 
sa compétitivité vis à vis de l'Amphipode. Les deux populations de proies tendent à se rencontrer plus fréquemment dans des zones refuges lorsque les prédateurs sont présents. Dans une autre grotte où n'existent pas de refuges pour les proies, le prédateur fait diminuer la densité des deux espèces. Il apparait qu'il est plus facile pour un prédateur, si la proie dispose de zone de refuge, d'envahir une communauté que d'arriver à un équilibre stable avec la proie. La persistence du système des proies et du système prédateur-proies est maintenue plus par les faibles effectifs des populations que par l'instabilité des coefficients d'interaction.

\section{ACKNOWLEDGEMENTS}

This work was partially funded by Biomedical Sciences Support Grant FR7-28-05 (NIH) to Northwestern University. D. Cook, N. Culver, J. Holsinger, T. Kane, J. Keith, and T. Van Zant assisted with field work. Residents of Lee County, Virginia extended various courtesies, especially permission to enter privately owned caves.

\section{LITERATURE CITED}

Addicott, J. F. 1974. Predation and prey community structure; an experimental study of the effect of mosquito larvae on the protozoan communities of pitcher plants. Ecology 55: 475-492.

Barr, T. C., Jr. 1961. Caves of Tennessee. Tennesse Department of Conservation and Commerce, Division of Geology, Bull. 64, 567 p.

Bishop, S. C. 1941. The Salamanders of New York. N. Y. State Mus. Bull. 324:1-365.

Brandon, R. A. 1971. North American troglobitic salamanders: some aspects of modification in cave habitats, with special reference to Gyrinophilus palleucus. Nat. Speleol. Soc., Bull. 33: 1-22.

Cooper, J. E. and M. D. Cooper. 1968. Cave-associated Herpetozoa. II. Salamanders of the genus Gyrinophilus in Alabama caves. Nat. Speleol. Soc., Bull. 30: 19-24.

Cramer, N. F. and R. M. May 1971. Interspecific competition, predation, and species diversity: a comment. J. theoret. Biol. 34:289-293.

Culver, D. C. 1970. Analysis of simple cave communities. I. Caves as islands. Evolution 24: 463-474.

Culver, D. C. 1971. Caves as archipelagoes. Nat. Speleol. Soc., Bull. 33: 97-100.

Culver, D. C. 1973a. Feeding behavior of the salamander Gyrinophilus porphyriticus in caves. Int. J. Speleol. 5: 369-377.

Culver, D. C. 1973. Competition in spatially heterogeneous systems: and analysis of simple cave communities. Ecology 54: 102-110.

Diamond, J. M. 1970. Ecological consequences of island colonization by Southwest Pacific birds. I. Types of niche shifts. Nat. Acad. Sci. (U.S.), Proc. 67:529-536.

Franz, R. and D. Slifer. 1971. Caves of Maryland. Maryland Geological Survey, Educ. Ser. No. $3,120 \mathrm{p}$.

Gilpin, M. R. and K. E. Justice. 1973. A note on non-linear competition models. Math. Biosci. 17:57-63.

Holling, C. S. 1965. The functional response of predators to prey density and its role in mimicry and population regulation. Mem. Entomol. Soc. Canada 45:1-60.

Holsinger, J. R. 1964. The biology of Virginia Caves, p. 57-74 in H. H. Douglas, Caves of Virginia, Virginia Cave Surrey, Falls Church, Virginia. 
Holsinger, J. R. and C. Holsinger. 1971. Observations on the population ecology of the cavernicolous amphipod crustacean Crangonyx antennatus Packard. Virginia J. Sci. 22:97. (abs.)

Hutchinson, G. E. 1959. Homage to Santa Rosalia, or why are there so many kinds of animals. Amer. Natur. 93:145-159.

Krebs, C. J. 1972. Ecology. The experimental analysis of distribution and abundance. Harper and Row, New York. 694 p.

Lawton, J. H., J. Beddington and R. Bonser. 1974. Switching in invertebrate predators, p. 141-159. In M. B. Usher and M. H. Williamson (eds.), Ecological stability. J. Wiley and Sons, New York.

Leopold, L. B. et al. 1964. Fluvial processes in geomorphology. Freeman, San Francisco.

Levin, S. 1974. Dispersion and population interactions. Amer. Natur. 108:207-228.

Levins, R. 1968. Evolution in changing environments. Princeton Univ. Press, Princeton, N. J. $120 \mathrm{p}$.

Levins, R. 1970. Complex systems, p. 73-88. In C. H. Waddington (ed.) Towards a theoretical biology: Drafts. Edinburgh Univ. Press, Edinburgh.

Levins, R. and D. C. Culver. 1971. Regional coexistence of species and competition between rare species. Nat. Acad. Sci. (U.S.), Proc. 68:1246-1248.

Levins, R., M. L. Pressick and H. Heatwole. 1973. Coexistence patterns in insular ants. Amer. Sci. 61:463-472.

MacArthur, R. H. 1972. Geographical ecology. Harper and Row, New York, N. Y. 269 p.

MacArthur, R. H. and E. O. Wilson. 1967. The theory of island biogeography. Princeton Univ. Press, Princeton, N. J. 203 p.

May, R. M. 1971. Stability in multi-species community models. Math. Biosci. 12:59-79.

May, R. M. 1972. Will a large complex system be stable? Nature 238:413-414.

May, R. M. 1973a. Stability and complexity in model ecosystems. Princeton Univ. Press, Princeton, N. J. 235 p.

May, R. M. 1973b. Time-delay versus stability in population models with two and three trophic levels. Ecology 54:315-325.

Maynard Smith, J. 1974. Models in ecology. Cambridge Univ. Press, Cambridge, 146 p.

Miller, R. S. 1967 . Pattern and process in competition. Adv. Ecol. Res. 4:1-74.

Mohr, C. E. and T. L. Poulson. 1966. The life of the cave. McGraw-Hill, New York. 232 p.

Murdoch, W. W. and J. R. Marks. 1973. Predation by coccinellid beetles: experiments on switching. Ecology 54:160-167.

Neill, W. E. 1974. The community matrix and interdependence of the competition coetticients. Amer. Natur. 108:399-408.

Paine, R. T. 1966. Food web complexity and species diversity. Amer. Natur. 100:65-75.

Paine, R. T. 1971. A short-term experimental investigation of resource partitioning in a New Zealand rocky intertidal habitat. Ecology 52:1096-1106.

Ricklefs, R. E. 1973. Ecology. Chiron Press, Newton, Mass. 861 p.

Roberts, A. 1974. The stability of a feasible random ecosystem.. Nature 251:607-608.

Slatkin, M. 1974. Competition and regional coexistence. Ecology 55:128-134.

Slobodkin, L. B. and L. Fishelson. 1974. The effect of the cleanerfish Labroides dimidiatus on the point diversity of fishes on the reef front at Eliar. Amer. Natur. 108:369-376.

Strobeck, C. 1973. N species competition. Ecology 54:650-654. 